\title{
Low prevalence of VRE gastrointestinal colonization of hospitalized patients in Manitoba tertiary care and community hospitals
}

George G Zhanel PharmD PhD 1-3,5, Godfrey KM Harding MD FRCPC ${ }^{1-7}$, Stuart Rosser MD $\mathrm{D}^{1,5}$, Daryl J Hoban PhD ${ }^{1,3}$, James A Karlowsky PhD ${ }^{1-3}$, Michelle Alfa PhD ${ }^{1,7}$, Amin Kabani MD ${ }^{1,3}$, John Embil MD ${ }^{1,4,5}$, Alfred Gin PharmD ${ }^{2,6}$, Trevor Williams $\mathrm{MD}^{1,5}$, Lindsay E Nicolle $\mathrm{MD}^{1,4,5}$

GG Zhanel, GKM Harding, S Rosser, et al. Low prevalence of VRE gastrointestinal colonization of hospitalized patients in Manitoba tertiary care and community hospitals. Can J Infect Dis 2000;11(1):38-41.

OBJECTIVE: To determine the prevalence of vancomycin-resistant enterococci (VRE) bowel colonization in hospitalized patients in Manitoba who had stool specimens collected for Clostridium difficile toxin and/or culture testing. DESIGN: Two tertiary care and five community hospitals in Winnipeg and three rural Manitoba community hospitals participated in this study. From January 1 to December 31, 1997 stool specimens, one per patient, submitted to hospital microbiology laboratories for $C$ difficile toxin and/or culture testing were screened for VRE on colistin-nalidixic acidvancomycin $(6 \mathrm{~g} / \mathrm{mL})$ (CNAV) agar plates. The study was divided into six, eight-week intervals. Stool specimens received in the first two weeks of each eight week interval were screened for VRE.

MAIN RESULTS: A total of 1408 stool specimens were submitted over the 48 -week study period. Sixty-seven (4.8\%) patients with VRE colonization of their lower gastrointestinal tract were identified. Three of the $67(4.5 \%)$ VRE isolates were Enterococcus faecium, with the remaining 64 (95.5\%) were Enterococcus gallinarum. The three vancomycin-resistant E faecium (VREF) (from two different Winnipeg hospitals) demonstrated the vanA genotype, and were resistant to vancomycin, teicoplanin and ampicillin. All three VREF isolates also demonstrated high level resistance to both gentamicin and streptomycin but were susceptible to quinuprisitin/dalfopristin and LY333328.

CONCLUSION: VRE colonization in hospitalized patients in Manitoba is infrequent and most commonly due to $E$ gallinarum. The prevalence of VREF colonization in the patients studied was $0.2 \%$ (three of 1408).

Key Words: Manitoba; Prevalence; Vancomycin-resistant enterococci

Pour le résumé, voir page suivante

\footnotetext{
${ }^{1}$ Departments of Medical Microbiology and Medicine, Faculty of Medicine, and ${ }^{2}$ Faculty of Pharmacy, University of Manitoba and Departments of ${ }^{3}$ Clinical Microbiology, ${ }^{4}$ Infection Control, ${ }^{5}$ Medicine and ${ }^{6}$ Pharmacy, Health Sciences Centre, and ${ }^{7}$ Department of Microbiology and Infectious Diseases, St Boniface General Hospital, Winnipeg, Manitoba

Correspondence and reprints: Dr George Zhanel, Department of Clinical Microbiology, Health Sciences Centre, MS673-820 Sherbrook Street, Winnipeg, Manitoba R3A 1R9. Telephone 204-787-4902, fax 204-787-4699, e-mail ggzhanel@pcs.mb.ca

Received for publication January 12, 1999. Accepted March 29, 1999
} 


\title{
Faible prévalence d'une colonisation gastro-intestinale par des entérocoques résistants à la vancomycine chez des patients hospitalisés dans des hôpitaux communautaires et de soins tertiaires du Manitoba
}

\begin{abstract}
OBJECTIF : Déterminer la prévalence d'une colonisation intestinale par des entérocoques résistants à la vancomycine (ERV) chez des patients hospitalisés du Manitoba chez lesquels on a recueilli des échantillons de selles pour y rechercher la toxine de Clostridium difficile et/ou pour les mettre en culture.

MODÈLE : Deux hôpitaux de soins tertiaires et cinq hôpitaux communautaires de Winnipeg, et trois hôpitaux communautaires localisés en zone rurale du Manitoba, ont participé à cette étude. Du $1^{\text {er }}$ janvier au 31 décembre 1997, des échantillons de selles, un par patient, envoyés au laboratoire de microbiologie de l'hôpital pour un dépistage de $C$. difficile et/ou une mise en culture ont été testés pour des ERV sur des plaques de gélose contenant une association vancomycine-acide nalidixique-colistin $(6 \mu \mathrm{g} / \mathrm{mL})$. L'étude a été divisée en 6 intervalles de 8 semaines. Les échantillons de selles reçus pendant les deux premières semaines de chaque intervalle de 8 semaines ont été examinés pour des ERV. PRINCIPAUX RÉSULTATS : Un total de 1408 échantillons de selles a été envoyé aux laboratoires pendant l'étude d'une durée de 48 semaines. Soixante-sept $(4,8 \%)$ des patients présentant une colonisation des voies intestinales basses par des ERV ont été identifiés. Il s'agissait de Enterococcus faecium dans trois des 67 isolats à ERV $(4,5 \%)$ et de Enterococcus gallinarum dans les 64 isolats restants $(95,5 \%)$. Les trois isolats de E. faecium résistants à la vancomycine (EFRV) (provenant de deux hôpitaux différents de Winnipeg) démontraient le génotype vanA, et étaient résistants à la vancomycine, à la teïcoplanine et à l'ampicilline. Les trois isolats de EFRV démontraient également un niveau de résistance élevée à la fois à la gentamicine et à la streptomycine, mais étaient sensibles à la quinuprisitine-dalfopristine et à LY333328.

CONCLUSION : La colonisation à ERV chez des patients hospitalisés du Manitoba n'est pas fréquente et est le plus souvent due à $E$. gallinarum. La prévalence d'une colonisation à EFRV chez les patients étudiés était de 0,2 \% (trois échantillons sur 1408).
\end{abstract}

$\mathrm{V}$ ancomycin-resistant Enterococcus faecium (VREF) accounts for up to $65 \%$ of $E$ faecium isolates in hospitalized patients across the United States and is endemic in many North American tertiary care institutions $(1,2)$. The management of these infections presents a significant clinical challenge because species of the genus Enterococcus, and in particular E faecium, are frequently resistant to several antimicrobial agents (3). High level penicillin resistance, high level aminoglycoside resistance and most recently vancomycin resistance are emerging as significant concerns in the treatment of enterococcal infections. This has prompted the development and evaluation of new antimicrobial agents such as quinupristin/dalfopristin and LY333328, a glycopeptide, which may offer activity against enterococci resistant to conventional therapy (2).

VREF is not endemic in Manitoba hospitals, and infection with VREF is extremely rare (4). However, the prevalence of VREF lower gastrointestinal tract (GIT) carriage, which frequently precedes infection $(5,6)$, is presently unknown for patients hospitalized in Manitoba. To determine whether the lack of VREF endemnicity correlated with an absence of lower GIT colonization, we assessed lower GIT carriage of VREF for patients hospitalized in 10 Manitoba hospitals from January 1 to December 31, 1997. Our study was consistent with Centers for Disease Control and Prevention guidelines (Atlanta, Georgia) that suggest surveillance programs for vancomycinresistant enterococci (VRE) be undertaken on an intermittent basis in areas where VRE is not known to be endemic (6). Isolates of VREF identified were phenotypically and genotypically characterized, and tested for their susceptibilities against a panel of antimicrobial agents.

\section{MATERIALS AND METHODS}

Enterococcus species isolate collection: Seven Winnipeg hospitals (Health Sciences Centre, St Boniface General Hospital, Misericordia General Hospital, Concordia General Hospi- tal, Victoria General Hospital, Grace General Hospital, and Seven Oaks General Hospital) as well as hospitals in the rural Manitoba communities of Brandon, Thompson and Portage la Prairie participated. The Health Sciences Centre and St Boniface General Hospital are tertiary care teaching hospitals affiliated with the University of Manitoba. The remaining eight hospitals are community hospitals.

The study was divided into six, eight-week intervals, and extended from January 1 to December 31, 1997. Each hospital collected stool specimens submitted for Clostridium difficile toxin and/or culture testing in the first two weeks of each eight week interval from patients in their hospitals. One stool specimen per patient was considered. Stool specimens were frozen following collection and shipped to one of two central reference laboratories (Health Sciences Centre and the St Boniface General Hospital) where they were thawed and planted onto blood agar (BA), colistin-nalidixic acid agar (CNA), and colistinnalidixic acid agar supplemented with $6 \mathrm{~g} / \mathrm{mL}$ vancomycin (CNAV). All plates were incubated at $35^{\circ} \mathrm{C}$ for $48 \mathrm{~h}$.

All morphotypes of suspected Enterococcus species were selected from BA, CNA or CNAV plates, stocked in skim milk at $-80^{\circ} \mathrm{C}$, and subsequently identified to species level using the following tests: Gram stain; motility assessment; catalase production; growth in $6.5 \%$ sodium chloride; L-pyrrolidonyl-naphthalamide hydrolysis; xylose, mannitol, arabinose and sorbitol utilization; bile/esculin growth/hydrolysis; pigment production; leucine aminopeptidase activity; and acidification of methyl- -D-glucopyranoside (7-9). The identification of all discrepant organisms was determined using DNA sequencing $(8,10)$.

Vancomycin resistance genotyping and epidemiological typing: DNA lysates of all isolated VREF were subjected to multiplex polymerase chain reaction $(\mathrm{PCR})$ to detect the presence of $\operatorname{van} \mathrm{A}, \operatorname{van} \mathrm{B}, \operatorname{van} \mathrm{C}-1$ and $\operatorname{van} \mathrm{C}-2 / \operatorname{van} \mathrm{C}-3$ genotypes (11), and pulse field gel electrophoresis (PFGE), following Smal digestion, for epidemiological tracing purposes (12). Simi- 
TABLE 1

Phenotypic and genotypic characteristics of the three vancomycin-resistant Enterococcus faecium (VREF) isolates identified as colonizers of the lower gastrointestinal tract of patients in Manitoba hospitals between January and December 1997

\begin{tabular}{lcccccccccc}
\hline & & & \multicolumn{9}{c}{ MICS $(\mu \mathbf{g} / \mathbf{m L})$} \\
VREF isolate & PCR profile & PFGE profile & V & T & A & S & G & C & Q/D & LY \\
\hline $1^{*}$ & vanA & 1 & 128 & 32 & 64 & $>4000$ & $>2000$ & $>32$ & 0.125 \\
$2^{+}$ & vanA & 2 & 256 & 32 & 64 & $>4000$ & $>2000$ & $>32$ & 0.125 & 0.5 \\
$3^{+}$ & vanA & 2 & 256 & 32 & 64 & $>4000$ & $>2000$ & $>32$ & 0.125 & 0.5 \\
\hline
\end{tabular}

*Isolate from a patient in Misericordia General Hospital, Winnipeg, Manitoba, collected between April 23 and May 7, 1997; ${ }^{\dagger}$ Isolate from a patient in Health Sciences Centre, Winnipeg, Manitoba, collected between June 18 and July 2, 1997. A Ampicillin; C Ciprofloxacin; G Gentamicin; LY LY333328; Q/D Quinupristin/dalfopristin; S Streptomycin; T Teicoplanin; V Vancomycin

lar PFGE patterns were defined as those that differed from one another by no more than one or two clearly visible bands (12).

Antimicrobial agents and susceptibility testing: All isolated VREF were tested for their susceptibility to vancomycin (Eli Lilly Canada Inc, Scarborough, Ontario), teicoplanin (Hoechst Marion Roussel Canada Inc, Montreal, Quebec), ampicillin (Wyeth Ayerst Canada Inc, North York), streptomycin (Pfizer Canada Inc, Kirkland, Quebec), gentamicin (Schering Canada Inc, Pointe-Claire, Quebec), ciprofloxacin (Bayer Inc, Etobicoke, Ontario), quinuprisitin/dalfopristin (Rhone Poulenc Rorer, Montreal, Quebec) and LY333328 (Lilly Research Laboratories, Indianapolis, Indiana) using the microdilution broth method and Mueller-Hinton broth as described by the National Committee of Clinical Laboratory Standards (Wayne, Pennsylvania (13). Before susceptibility testing all Enterococcus species were subcultured twice onto blood agar.

\section{RESULTS}

The number of stool specimens evaluated in the first two weeks of each eight week period between January 1 and December 31, 1997 ranged from 187 to 265 . A total of 1408 stool specimens were tested. Sixty-seven of the 1408 (4.8\%) hospitalized patients evaluated had VRE colonization of their lower GIT. Three of the 67 (4.5\%) VRE identified were E faecium, while the remaining 64 isolates (95.5\%) were Enterococcus gallinarum. Three of 1408 (0.2\%) patients hospitalized in Manitoba, who had a stool specimen submitted for $C$ difficile testing during the study period, were colonized with VREF. One isolate of VREF was identified at the Misericordia General Hospital, a Winnipeg community hospital, between April 23 and May 7, 1997. The two remaining isolates of VREF were identified between June 18 and July 2, 1997 at the Health Sciences Centre, a Winnipeg tertiary care hospital.

All three VREF identified possessed the vanA genotype (Table 1). The two isolates of VREF, from the Health Sciences Centre, possessed the same PFGE pattern while the third isolate, collected from a patient at the Misericordia General Hospital, had a different PFGE pattern (Table 1). Both PFGE patterns have been previously identified in VREF isolated in Manitoba (unpublished data), suggesting they may have been acquired locally or nosocomially. Using NCCLS serum breakpoints (14), the three isolates of VREF demonstrated uniform resistance to teicoplanin, ampicillin, streptomycin, gentamicin, and ciprofloxacin, but were sensitive to quinuprisitin/dalfopristin and LY333328 (Table 1).

\section{DISCUSSION}

Enterococci are normal constituents of the human GIT, and may also colonize the oral cavity, vagina, biliary tract and upper respiratory tract of healthy people. Most clinical isolates of enterococci represent colonization, not infection (15). Enterococci may however cause infection, most commonly urinary tract infections (15). Cholecystitis, cholangitis, peritonitis, septicemia, endocardititis, meningitis and wound infections have also been documented (15). The GIT is the major reservoir for enterococci, and serves as the source of dissemination. However, the ability of enterococci to survive on environmental surfaces for extended periods (up to a week) can also facilitate their spread (15).

Traditionally, enterococcal infections have been treated with the penicillins, usually in combination with an aminoglycoside for serious infections. However, with penicillin and aminoglycoside resistance rates increasing vanconiycin is now often used to treat enterococcal infections. VRE were extremely rare before 1988 with just two isolates (MIC greatern than $100 \mathrm{~g} / \mathrm{mL}$ ) documented in the previous two decades $(16,17)$. In 1988 , VRE began to emerge as a clinical concern, with the description of 55 clinical isolates of VRE (seven Enterococcus faecalis and $48 \mathrm{E}$ faecium) (MICs greater than $64 \mathrm{~g} / \mathrm{mL}$ ) from 22 British patients with renal impairment (18). In 1993, the American National Nosocomial Infections Surveillance (NNIS) system reported an increase in the incidence of nosocomial VRE from $0.3 \%$ in 1989 to $7.9 \%$ in 1993 (19). Many scientific publications from the United States and Europe have followed with reports of as many as $65 \%$ of $E$ faecium isolates being vancomycin resistant in some American hospitals (1). The epidemiology of VRE in Canada before 1997 has been succinctly summarized (20), with the first isolate of VRE reported in Edmonton in 1993 and the first VRE outbreak, involving 38 patients, occurring in a Toronto hospital in 1995. A 1996 Canadian VRE surveillance study demonstrated a VRE (E faecalis or E faecium) point prevalence of $0.7 \%$ overall (26 of 3773 ), $0.1 \%$ in nonendemic hospitals, $3.7 \%$ in endemic hospitals and $5.3 \%$ in endemic patient groups within endemic hosptials (21). Twenty-three of the 26 patients identified in this study were from a single tertiary care institution with all isolates (three $E$ faecalis and 23 E faecium) being colonizers (21).

VRE were not identified in a previous study over a fourmonth period in 1995 at the Health Sciences Centre in Winnipeg, one of the 10 Manitoba hospitals included in this survey 
(4). As a continuation of that study, we added six additional Winnipeg and three rural hospitals. Only three isolates, from two hospitals, representing VREF colonization of patients hospitalized in Manitoba were identified (0.2\%). Isolates of vancomycin-resistant $E$ faecalis were not identified.

\section{CONCLUSIONS}

We conclude that VRE colonization of patients hospitalized in Manitoba remains infrequent; however ongoing surveillance will be necessary to ensure adequate knowledge of changing trends in VRE epidemiology. A simple and effective technique to screen for the emergence of VRE is to evaluate stool specimens submitted for $C$ difficile analysis.

ACKNOWLEDGEMENTS: This study was supported by a grant from the Manitoba Medical Service Foundation. Dr Zhanel is supported by a Merck Frosst Chair in Pharmaceutical Microbiology. We gratefully acknowledge each participating Manitoba hospital and their laboratory staff as well as the Cadham Provincial Laboratory in Winnipeg.

\section{REFERENCES}

1. Currie BP, Gnass S, Levi MH. A hospital based stool culture survey to detect vancomycin resistant enterococcus (VRE) Utility and application. Infect Control Hosp Epidemiol 1995;16(Suppl):P18. (Abst 15)

2. Gin AS, Zhanel GG. Vancomycin resistant enterococci (VRE). Am Pharmacother 1996;30:615-24.

3. Bacquero F. Gram-positive resistance: challenge for the development of new antibiotics. J Antimicrob Chemother 1997;39(Suppl A):1-6.

4. Embil J, Zhanel G, Kabani A, Nicolle L. Low prevalence of gastrointestinal colonization with antimicrobial resistant bacteria in high risk units in a Canadian tertiary care centre. Can Infect Dis 1996;7:307-12.

5. Edmond MB, Ober JF, Weinbaum DL, et al. Vancomycin-resistant Enterococcus faecium bacteremia: risk factors for infection. Clin Infect Dis 1995;20:1126-33.

6. Recommendations for preventing the spread of vancomycin resistance. MMWM Morb Mortal Wkly Rep 1995;44(RR1-12):1-19.

7. Devriese LA, Pot B, Kersters K, Lauwers S, Haesebrouck F. Acidification of methyl-a-D-glucopyranoside: a useful test to differentiate Enterococcus casseliflavus and Enterococcus gallinarum from Enterococcus faecium species group and from Enterococcus faecalis. J Clin Microbial 1996;34:2607-8.
8. Turenne CY, Hoban DJ, Karlowsky JA, Zhanel GG, Kabani AM. Screening of stool samples for identification of vancomycinresistant enterococcus isolates should include the methylalpha-D-glucopyranoside test to differentiate nonmotile Enterococcus gallinarum from E. faecium. J Clin Microbiol 1998;36:2333-5.

9. Landman D, Quale JM, Oydna E, et al. Comparison of five selective media for identifying fecal carriage of vancomycin-resistant enterococci. J Clin Microbiol 1996;34:751-2.

10. Williams AM, Rodrigues UM, Collins MD. Intragenenic relationships of enterococci as determined by reverse transcriptase sequencing of small-subunit rRNA. Res Microbial 1991;142:67-74.

11. Dutka-Malen S, Evers S, Courvalin P. Detection of glycopeptide resistance genotypes and identification to the species level of clinically relevant enterococci by PCR. J Clin Microbiol 1995;33:24-7.

12. Clark NC, Cooksey RC, Hill BC, Swenson JM, Tenover FC. Characterization of glycopeptide resistant enterococci from US hospitals. Antimicrob Agents Chemother 1993;37:2311-7.

13. National Committee of Clinical Laboratory Standards. Methods for Dilution Antimicrobial Susceptibility Testing for bacteria That Grow Aerobically: Approved Standard M7-A4. Wayne: NCCLS, 1997.

14. National Committee of Clinical Laboratory Standards. Performance Standards for Antimicrobial Susceptibility Testing; Eighth Informational Supplement M100-S8. Wayne: NCCLS, 1998.

15. French GL. Enterococci and vancomycin resistance. Clin Infect Dis 1998;27(Suppl 1):S75-83.

16. Toala P, McDonald A, Wilcox C, Finland M. Susceptibility of group D Streptococcus (Enterococcus) to 21 antibiotics in vitro with special reference to species differences. Am J Med Sci 1969;258:416-30.

17. Harwick HJ, Kalmanson GM, Guze LB. In vitro activity of ampicillin or vancomycin combined with gentamicin or streptomycin against enterococci. Antimicrob Agents Chemother 1973;4:383-7.

18. Uttley AHC, Collins CH, Naidoo, J George RC. Vancomycinresistant enterococci. Lancet 1988;i:57-8.

19. Nosocomial enterococci resistant to vancomycin - United States, 1989-1993. MMWR Morb Mortal Wkly Rep 1993;42:597-9.

20. Emerging epidemiology of vancomycin-resistant enterococci in Canada. Can J Infect Dis 1997;8:182-5.

21. Ofner-Agostini ME, Conly J, Paton S, et al. Vancomycin-resistant enterococci (VRE) in Canada - Results of the Canadian nosocomial infection surveillance program 1996 VRE point prevalence surveillance project. Can J Infect Dis 1997;8:73-8. 


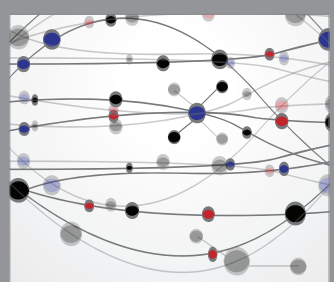

The Scientific World Journal
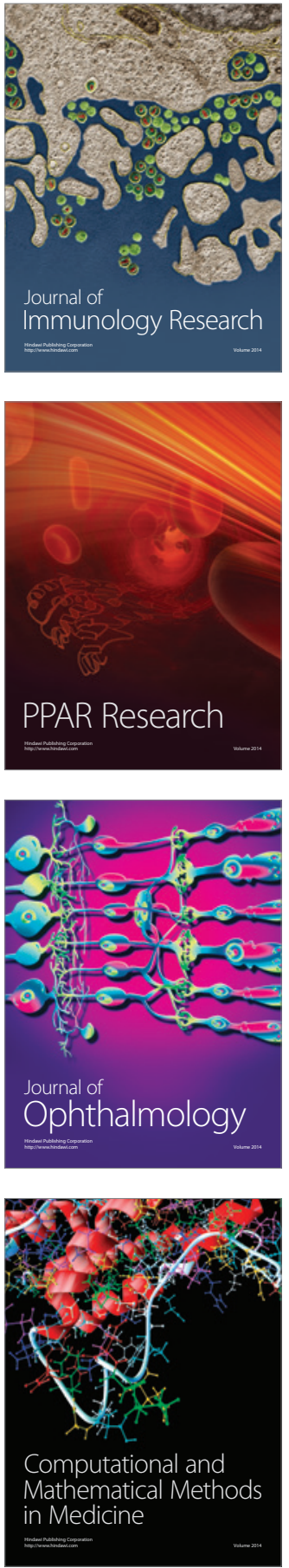

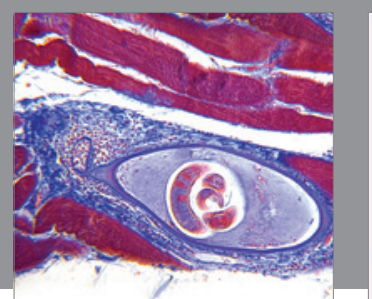

Gastroenterology Research and Practice

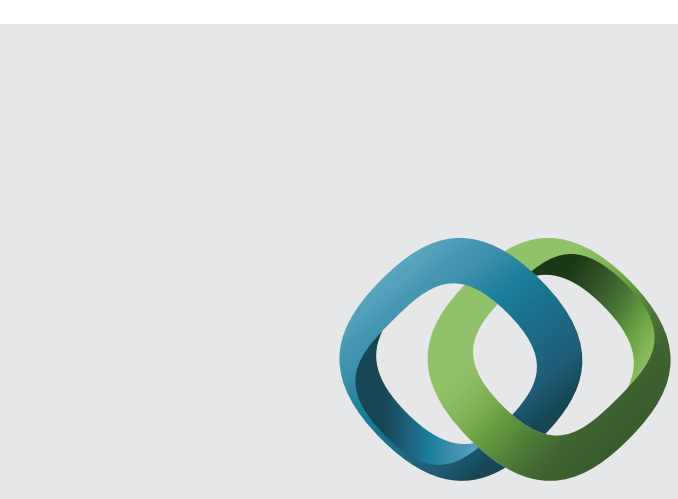

\section{Hindawi}

Submit your manuscripts at

http://www.hindawi.com
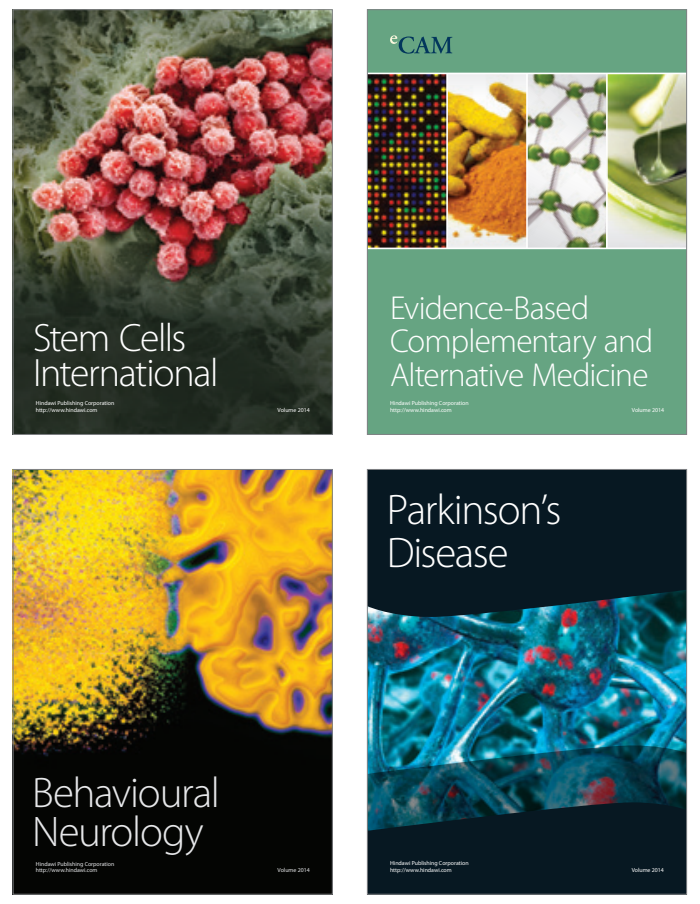
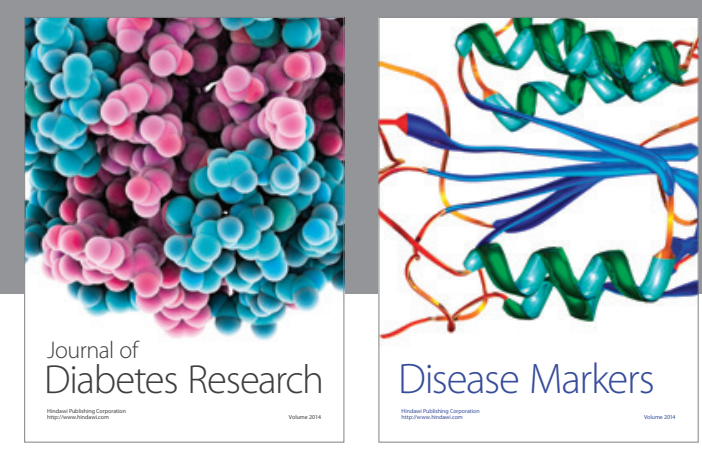

Disease Markers
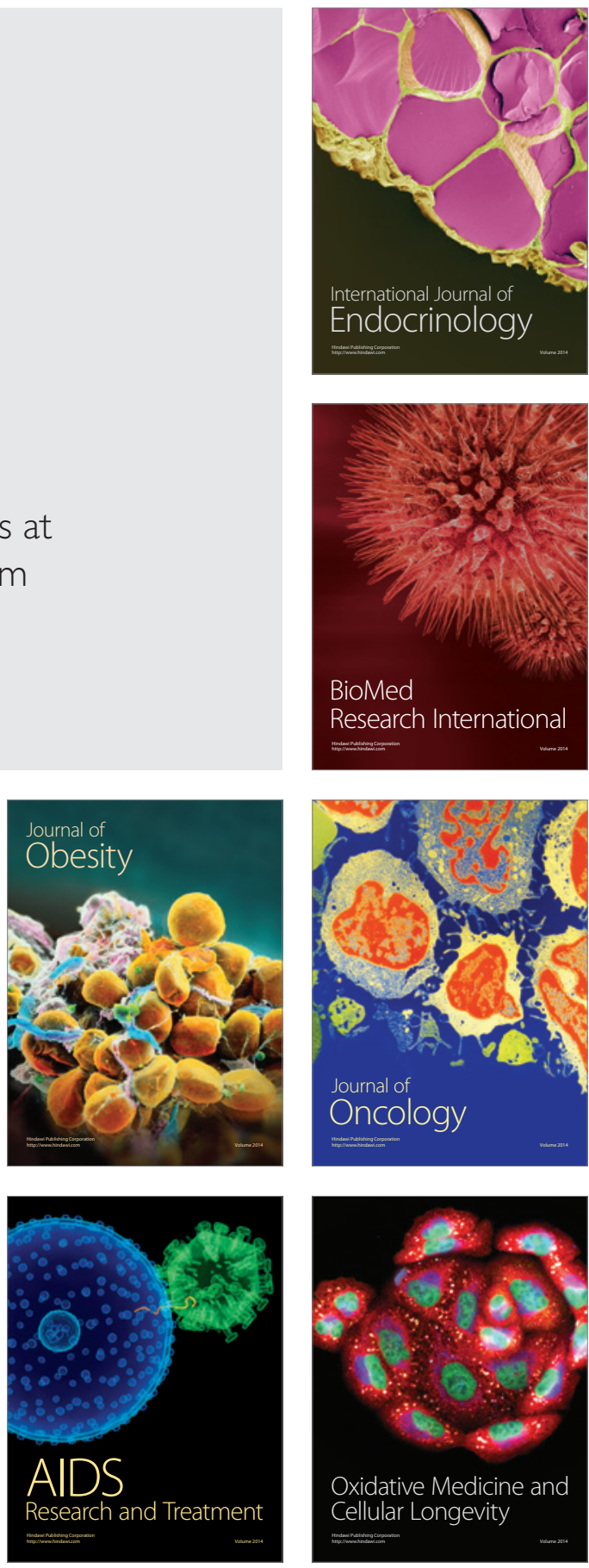